Article

\title{
Performance Appraisal in Universities-Assessing the Tension in Public Service Motivation (PSM)
}

\author{
Łukasz Sułkowski ${ }^{1, *(D)}$, Sylwia Przytuła ${ }^{2, *(D)}$, Colin Borg ${ }^{3}$ and Konrad Kulikowski 4 \\ 1 Department of Higher Education Institutions, Jagiellonian University, 30-348 Kraków, Poland \\ 2 Human Resource Management Department, Wrocław University of Economics and Business; \\ 53-345 Wrocław, Poland \\ 3 Department of Public Policy, Office of Registrar, University of Malta, 2080 MSIDA, Malta; \\ colin.borg@um.edu.mt \\ 4 Faculty of Management, University of Social Sciences, 90-113 Łódź, Poland; kkulikowski@san.edu.pl \\ * Correspondence: lukasz.sulkowski@uj.edu.pl (Ł.S.); sylwia.przytula@ue.wroc.pl (S.P.)
}

Received: 25 May 2020; Accepted: 29 June 2020; Published: 1 July 2020

\begin{abstract}
Performance appraisal (PA) has become a prominent feature on the agenda of higher education institutions (HEIs). However, the traditional culture of the typical university is based on individual commitment, scientific teamwork, dedication to public service and intrinsic motivation of the academic staff, all of which are the essential components of public service motivation (PSM). By interviewing key informants from three public universities, the purpose of our research was to identify various tensions between PA and PSM, by asking what is the impact of PA on PSM of academics in public HEIs. Our findings have shown that the purposefulness of PA activities may not be fully understood by public HEI management and academics. The existing tensions between PA normative aims of motivation and fair evaluation and its descriptive effects of increasing bureaucracy and dissatisfaction might undermine PSM, an essential driving force that motivates academics to work in public HEIs.
\end{abstract}

Keywords: performance appraisal; Public Service Motivation (PSM); Higher Education Institutions (HEIs)

\section{Introduction}

Performance appraisal (PA) is only one facet of a performance management (PM) framework in an organisation and is the process of assessing an employee's performance towards achieving institutional performance targets. PA focuses on the work, the employee's expectations, development, productivity, motivation effort and the attitude of staff towards work [1]. Over the last few decades, the European university system has undergone a profound change, caused by the structural transformations of the Bologna Process and with the intention to increase research quality and make universities more comparable, competitive, dynamic and transparent [2-4]. Various forms and practices of performance appraisal have been implemented by hundreds of universities throughout the Western world [5-8].

Treating universities as business organisations is associated with neoliberalism, and the new public management (NPM) and performance appraisals tend to be perceived as black boxes in a larger NPM 'machine' [9]. The growing importance of the market and competition in the higher education sector brings with it an increase in the accountability of the university and its employees $[10,11]$. However, the traditional culture of the university is based on a large extent on Merton's CUDOS(communism, universalism, disinterestedness, organized skepticism) ethos reflected in individual commitment, scientific teamwork, dedication and intrinsic motivation over extrinsic rewards of the academic staff $[12,13]$, which are components of public service motivation (PSM). PSM is a particular form 
of prosocial motivation that is animated by specific dispositions and values arising from public institutions and missions [14] or as a subset of prosocial motivation in which the intended beneficiary of an individuals' actions is the broader community or society at large. Public service motivation (PSM) consists in motivational factors that are unique in professions that serve the public $[15,16]$.

Researchers have confirmed relationships between public service motivation and positive outcomes such as job satisfaction $[17,18]$, individual and organisational performance [19], organisational and job commitment, and low turnover [20]. Higher PSM is also associated with higher performance in the higher education sector, and this result is more evident the longer the students have been taught by a high-PSM teacher [12]. Other research has demonstrated that PSM is positively correlated with job satisfaction, particularly when there is a good fit between the person with the job tasks and with organisational culture [21]. Although there is a growing stream of research which suggests that the most important method to increase research performance is to provide greater organisational support and clear rules of performance for academics in their teaching, scientific and research work [22,23], the effect of PM on PSM in the higher education sector remains underrepresented in research and should be explored further.

We assume that the huge proportion of academic employees in public higher education institutions (HEIs) might see work for public universities as a form of mission, a vocation and a special service to society. Nevertheless, when PA systems are introduced in HEIs, this aspect of academic PSM might not have the desired effect and, on the contrary, leads to unintended consequences. One classical example would be the motivation of academics to collaborate with colleagues in original and groundbreaking research projects might turn into unnecessary pressure to publish more papers than their colleagues in order to ensure that they will be rewarded with bonuses and an improved salary package. Therefore, the purpose of this paper is to identify various tensions in PA in three European universities and answer the general research question: How PA might influence PSM? To address some of the tensions regarding the links between public service motivation (PSM) and individual performance appraisal, we proposed a three-phase development model for PA (as specified in Figure 1), as well as the unintended consequences of PA for PSM for academic employees in public HEIs (the term 'higher education institutions' means in our research 'public universities').

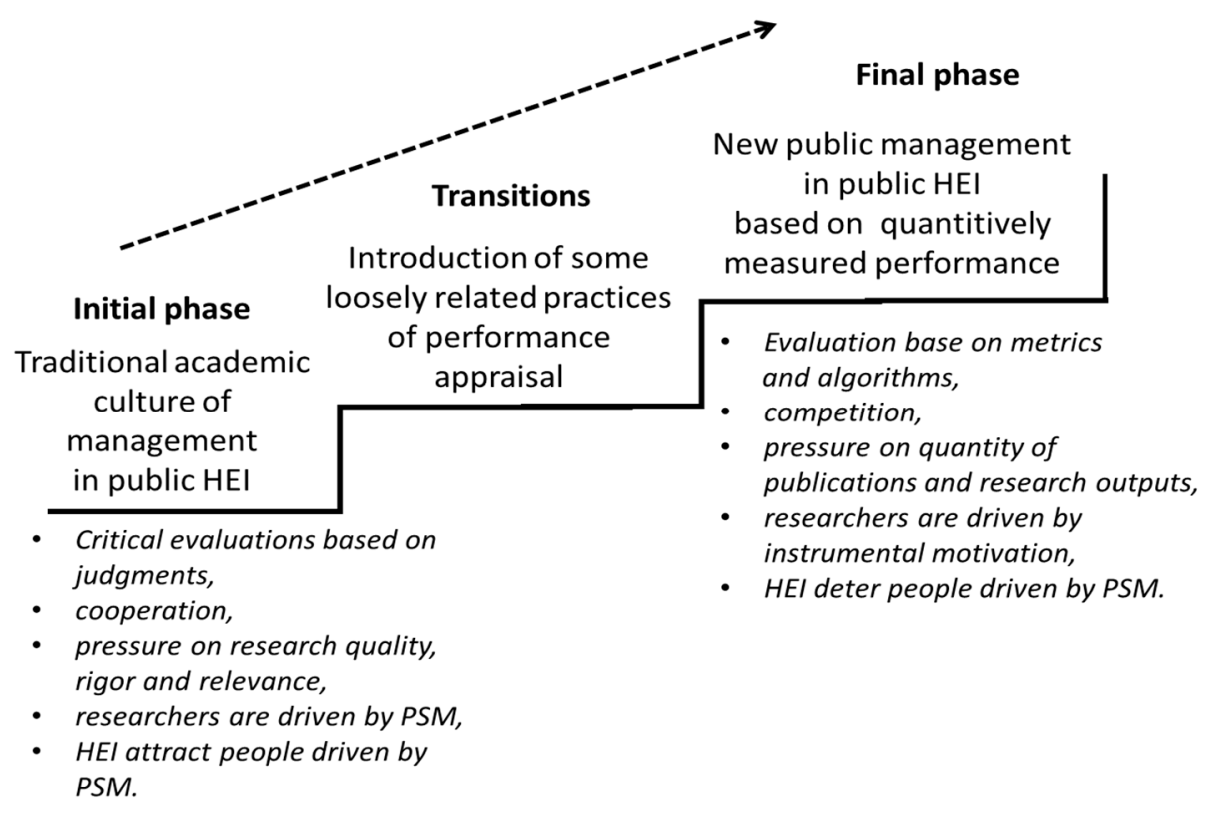

Figure 1. The conceptual model of the development of PA (performance appraisal) in public HEIs (higher education institution) and its possible unintended consequences for PSM (public service motivation) of an academic employee. 
In Figure 1, we put forward our original conceptual model in the form of three steps that most public HEIs must transpose from the so-called traditional HEIs' way of human resources (HR) management toward the new public management HR management that compels results, performance measures and accountability. This figure allows us to establish a conceptual framework for our research questions and help us to analyse the consequences of PA on PSM of researchers in public universities.

As the black arrows in Figure 1 indicate, the journey from traditional academic culture to new public management starts from the traditional academic system of prestige and social relations and goes through the transitional phase of initial development of some loosely related forms of performance measurement to a performance appraisal system fully integrated in HR management in academia. The presumed aim of this transformation is to improve accountability of HEIs and manage them in more effective ways. However, as we propose at the lower part of Figure 1, as the HEIs move forward, the measurement defining academics status as well as the other unintended consequences of PA might turn PSM of academics into instrumental motivations. Thus, we suggest that besides desired changes in HR management such as accountability, objective measurement, the process from initial to final phase is also related to the unintended changes in the academic job characteristic leading to substitution of PSM by instrumental motivation to attaining a high enough evaluation score. Obviously, this model in Figure 1 is rather heuristic, specific phases might have different lengths and courses depending on the cultural or organisational context, but the general mechanism seems to be always the same; as HEIs approach the final phase of incorporating NPM, the characteristic of job changes and PSM of academics might decrease. With this conceptual model as a background for our analysis, we would like to highlight that, besides some normative positive consequence as accountability and objective measurement, the introduction of NPM into academia might also have some unintended negative consequences in the form of changing the nature of the job and diminishing public service motivation of researchers.

Therefore, because of possible unintended consequences, the issue under consideration is whether these phases in Figure 1 are truly moving in the right direction and is it really desired to aim to reach the final phase? Therefore, in this study, we aimed to expand our understanding of how values develop performance appraisal in HEIs which might affect PSM. Further investigation into the development of PSM may improve the manner in which we understand and apply the PSM concept to performance management in HEIs. For instance, if prosocial goals, such as helping others, devotion and dedication to work, form the foundation of PSM, universities might provide an additional evaluation criteria in individual PA of their employees just to encourage such attitudes and behaviour.

\section{Literature Review}

\subsection{Adapting Performance Management Practices from the Business Sector to Public Institutions}

Public higher education institutions (HEIs) should adopt performance management practices from business settings. This mantra is repeated over and over in NPM literature, and when the HEI performance is not satisfactory for stakeholders, then stubbornness to adopt best management practices from the private sector is seen as one of the biggest problems [24,25]. However, before we adopt performance management practices from businesses, we might first ask if it is true that businesses have the best practices in performance management to offer HEIs. Although there are many popular beliefs concerning this matter and anecdotal evidence for the profound impact of PM on the performance of individual and business organisations, there is almost no empirical evidence that PA improves performance in organisations that use them. There are, however, more and more reports showing that PA has become a bureaucratic burden that sparks frustration in managers and employees altogether without a significant positive impact on performance [26-31].

Murphy [28] also states that 'performance management should die', highlighting the disappointment that stems from PA systems in business settings, providing four reasons why performance evaluation is not effective. First of all, the distribution of performance is not Gaussian 
(normal), but rather Paretian (power-law) [32], thus assessment done under the assumption of a normality of performance distribution is pointless. Secondly, due to the vast amount of subjectivity and errors in performance ratings, it is almost impossible to provide valid and reliable measurements of individual performance. Thirdly, the performance feedback has limited use for the employee and is often rejected or seen as inappropriate. Fourthly, performance evaluations have limited utility for organisations, e.g., employee ratings are intended to be used for payment purposes, but most organisations, for varying reasons, are reluctant to establish strong links between performance level and pay [28].

Furthermore, PA often neglects employee reactions, their perception of satisfaction, accuracy and the fairness of the system. Whereas rate reactions are crucial aspects of effective performance management [33,34], an appraisal system that sparks dissatisfaction and is seen as unfair is doomed to failure [35]. In conclusion, it is not clear how PA functions in private organisations and how the practice of evaluating individual employees influences the performance of employees and organisations as a whole [26,36,37]. As Schleicher et al. [30] concluded, there is a great deal yet to know about the effectiveness of PA.

\subsection{Performance Appraisal in HEIs}

Although there is no conclusive evidence to support the argument that PA improves both individual and organisational performance, and there are even substantiated conclusions to support the idea that only measuring the concentration-performance relationship is the cause for the lack of improvement in performance levels, the PA systems are largely implemented across HEIs. Various forms and practices of PA have been implemented by hundreds of universities throughout the Western world [8]. As PA is commonly used in HEIs, it is still seen as a highly controversial topic [5], and researchers are ambivalent toward performance norms and performance expectations [38].

PA might be particularly problematic in public HEIs, as it is assumed that public-sector employees are dictated by service motivators-public service motivation (PSM). Ritz, Brewer and Neumann [39] stated that remuneration based on PA should not be used if the employer is aiming to attain a high level of public service motivation, whereas Gerrish [27], in his metanalysis, reveals only a minimal effect of performance management practices on public organisational performance. Due to the pressure to appear to be more productive, which is the result of measures taken to deal with inadequate performance levels, researchers might tend to play it safe by preferring to publish lower-quality but less-risky, less-ambitious research articles or reports; this might, in the long term, result in researchers being less creative [24].

Moreover, the adoption of PA practices might be forced by external pressures for legitimacy and accountability; for example, grant funders' expectations for rational budget spending do not come from the needs of researchers [40]. Although performance measurement in terms of accountability and budgeting are important, we cannot forget that relying only on the arbitrarily chosen performance indicators without taking into consideration the broader issues might be problematic in the university context, especially in the knowledge generation process, which is the ultimate goal of HEIs. Nevertheless, it is easy to measure performance indicators in order to reach a goal post, but to lose sight of the real purpose of this measurement [41].

All these concerns lead to a situation whereby a performance measurement might be used by universities in a ceremonial and symbolic manner as a box-ticking practice [42], aimed at legitimising themselves externally as research-oriented institutions, not with the rational aims of making better local decisions or to foster human resource development. However, reporting performance measures for external accountability purposes might be loosely related to using performance measures for rational decision-making and performance improvement [42]. 


\subsection{The Effects of the PA System on HEIs}

It seems clear from the abovementioned literature review that PA and measurement pose a serious challenge for public HEIs' management, partially because they are a threat to PSM. Academic employees might lose their PSM when injected into the PA and bureaucracy. We suggest that most public HEIs are blinded with the overwhelming need to follow and implement 'business solutions' into public services. They tend to implement a different method for performance measurement, hoping that these practices lead to an eventual improvement in academic performance, whereas the real effect of these performance measurement practices might be quite the opposite. A public academic employee forced into participation in a PA system might simply devalue their previous PSM and become cynical to future PA systems.

Therefore, this study explored the perception of PA procedures in public universities. It seeks to determine whether PA helps or hampers performance. To determine the situation, the authors analysed PAs in three universities in order to establish a clearer picture of the contribution of PA amongst employees in public universities. This paper seeks to extend the understanding of the following How, who and why of HEIs' PA, by asking the following research questions (RQ):

RQ 1. How is PA used-symbolic vs. rational PA?

1.1. Is the PA system seen as symbolic or rational? Therefore is PA used only to 'symbolise' to external sites (e.g., government, funding agencies, etc.) that universities acts in a rational, progressive and accountable manner but does it have any rational use for the purposes of HR development?

$\mathrm{RQ} 2$. Who is the appraised individual vs. collective performance?

2.1. What kind of PA initiatives were introduced and implemented in universities?

2.2. Is the PA individual or collective?

RQ 3. Why is performance management used-administrative vs. developmental purposes?

3.1. Is there a tension between universities and governmental agencies' views on performance appraisal?

3.2. Is there an internal need for rational management by performance indicators or external pressure (e.g., government) forcing universities to carry out PA?

RQ 4. How is PA perceived by the academic community-A tool for performance improvement vs bureaucratic machine?

4.1. Which factors inhibit universities in the PA process? Are these internal (e.g., academics employee attitudes) or external ('bad' regulations related to academic performance management, lack of funding) factors?

4.2. Is PA focused on accountability and assessment only or on development of employee performance? i.e., is a PA a part of the whole performance management system (e.g., along with feedback, training, mentoring and goal setting) or is a PA the end in itself?

\section{Methodology}

The research methodology used was qualitative and was based on a comparative analysis of university PM case studies [43] conducted in Poland and in Malta (see characteristics of the universities in Appendix A). That was a convenient sample, as the authors are employed at these universities. The choice of the universities was based on two essential parameters: first, the contextual legal conditions in the country where the universities operate are currently changing. Legislative changes have an influence on both the strategic endeavours and the modus operandi of universities. Secondly, the ranking category of the three universities is considered as middle of the range; therefore, the analysis is to shed light on a contextual situation that is quite similar. HEIs in Poland have gone through the current transformation and reform of higher education from 2016 to 2019 (Law 2.0), and Malta's contextual scenario is based on two main fundamental developing circumstances: the introduction of the Academic Effort in 2007 and the proposed University Act for the only public university, the University of Malta, back in 2016. 
The choice was limited to three universities in order to analyse in detail the findings and to include a substantial number of interviewers from each of the 3 universities. The more universities that are included, the less in-depth studies can be achieved. Moreover, these universities were chosen to fulfil the criteria of data saturation in our study. Data saturation refers to the situation in the research process when no new information is discovered in data analysis, and this redundancy signals to researchers that data collection should be stopped [44]. We needed data from 17 key informants to see the redundancy and obtain the significant level of qualitative data saturation $[45,46]$. Lacking the interviews process from one of the Polish public universities will not lead us to data saturation, we simply would not identify redundancies in data [47]. On the other side, we could not add a second public university from Malta, because, in this country, there is only one public university.

The main data for the universities' case studies are from interviews additionally supported by participant observation. Depth of analysis is important when dealing with subject matters that are transdisciplinary in nature; i.e., public service motivation in higher education. That is why data for each of the university case studies were collected using two complementary methods which belong to ethnographic studies [48]: in-depth interviews with 'key informants' [49] and participant observation. Participant observation can be used as a way to increase the validity [48] of the study, as observations may help the researcher have a better understanding of the context and phenomenon under study [50]. When combined with the interviews, participant observation was the qualitative research tool that provided the authors as academics and as managers with an opportunity to immerse the findings in the context of the universities under study. Moreover, the authors" "insider perspective," that is based on their long-term experience in scientific and research field at these three universities and their embeddedness in the context of higher education, helped to place the data/information received from key informants in the right category of issues (e.g., financial motivation, performance appraisal, bureaucratic obstacles).

Given that the interviews were conducted with academic leaders hailing either from the Rectorate's office or from several sub-units within the universities, the active participatory role of the authors was crucial to understand the dynamics of the answers provided. Participant observation was conducted in parallel with the interviews, and therefore in the last quarter of the year 2019. However, this observation is much more mature as it follows from long-term experiences of three authors as employees, researchers, professors of these universities whose experience exceeds more than 15 years of being employed in these institutions.

Based on the literature analysis, the problem and 4 research questions were formulated and the subsequent appropriate research tools (interview questionnaire with 10 open questions) were prepared. After three interviews (piloting) conducted with key informants, the authors corrected the survey tool and sent it back to be translated into English, for the purpose of conducting interviews with respondents from the University of Malta.

Interviews at all 3 universities were conducted ( 6 from Wrocław University of Economics, 5 from Jagiellonian University, 6 from the University of Malta), with 17 officials representing the highest and middle levels of management. The authors applied a technique of key informant because our respondents, by virtue of their qualifications, held formal positions in the organisation and are able to give researchers a great deal of detailed information and provide a broader perspective of what is happening in their organisational environment. It is important to note that, based on key informant opinions, we might draw conclusions about the role of PA at an organisational level, but also how in key informant opinions PA might affect researchers on an individual level. Key informants, thanks to their positions within university structures and unique outlook of university policy, might provide valid prediction of PA effect on individual academic employees. The composition of the research sample is indicated in Table 1. 
Table 1. Research sample, $n=17$.

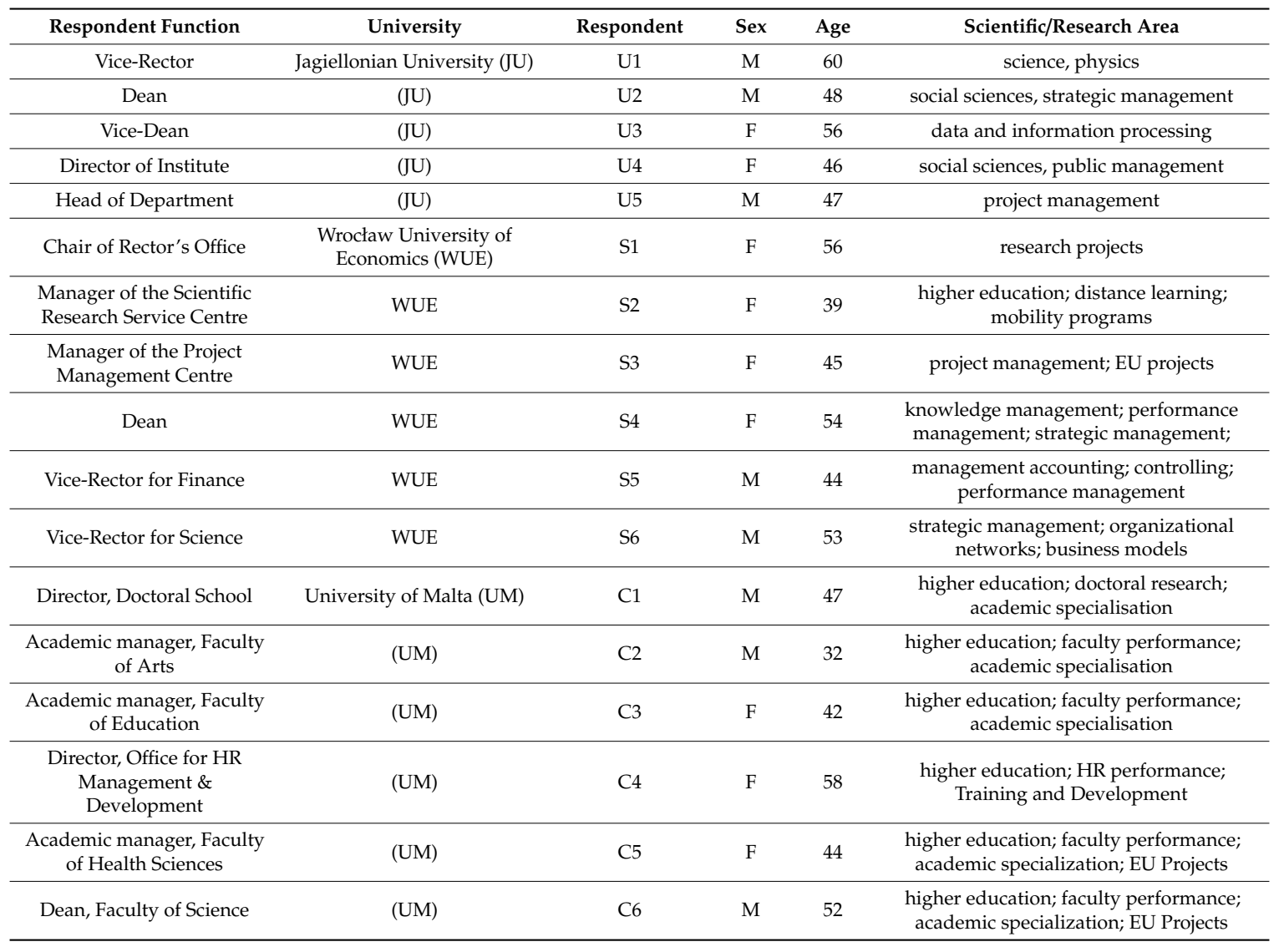

The transcripts of the interviews were analysed using NVivo version 12 . The answers to the questions regarding the researched problem in the studied universities were extracted.

The research sample of universities counts only 3 of them selected deliberately for comparative analysis. The research problem performance appraisal in universities viewed by the lenses of Public Service Motivation is a fairly universal issue found in the majority of universities. Increase of accountability, pay for performance practices and general development of New Public Management in HEIs influence performance appraisal growth. Qualitative sample of 3 objects is heterogenous and differentiated, which illustrates the universal character of the growing impact of PA in public universities. In all three cases, the insider perspective and participant observation has been used. The authors of the paper are insiders in the 3 universities, and they are included in sample. This has the advantage of allowing the authors to be more reflective and critical in interviews, and the interviewees would be more likely to trust the authors since they are their colleagues and peers [51].

However, the results could not be generalised due to the qualitative sample and subjective biases. The data can be utilised as a comprehensive and reflective material illustrating the problem. The key informants are academic managers, but at the same time, researchers in their own institution. This provides them with a dual perspective since they have a unique, critical approach of promotors but also users of PA in HEIs. Future research could use the research results of PA in HEIs and make testing of hypothesis on representative samples in quantitative schemes.

\section{Results}

Below we presented the analysis of interviews with our key informants, which is supported by their quotes (see all extracted quotes in Appendix B).

Ad. Research Question 1(RQ 1). How is PA used-symbolic vs. rational PA? 
The first theme assessed by the authors revolved around the nature of the PA system and how it is implemented. The issue considered was whether a PA is more a symbolic or a rational exercise. The results of the interviews demonstrate that there are formal procedures for assessing employees, but they do not translate into a realistic and practical system of remuneration and employee development.

An evident conclusion was that the universities lack a comprehensive appraisal and assessment system. To the contrary, PA tools are confined to parameterisation, as mentioned by one respondent:

'You can't talk about the system-what we do results from the parameterisation and indicators that were shown there. There was also no comprehensive assessment attempt at a university other than parameterization' [S1].

The lack of a holistic approach was evident in all the universities; in most instances there are only sporadic elements or ad hoc tools on which a comprehensive system can be built. One of our key informants noted: 'We cannot say that we have a system-there are only elements on which this system can be built' [S4].

The reason articulated for the lack of a comprehensive approach was that PA is still in its infancy, as was mentioned by a respondent: 'We are still in our infancy, but all the tools created are moving towards the evaluation of scientific performance' [S3]. The development of the scientific capabilities of a resident academic member of staff is nonexistent, given that PA is confined only to the promotions exercise. One respondent said that: 'I am not aware that my university has other measures than those used for the promotion system of a resident academic' [C1].

Another aspect that was highlighted by the universities' key informants is the lack of a system and cyclical approach in periodic assessment, as mentioned by a respondent: 'We can't talk about a systemic approach, we only have tools (...). Some scholars are evaluated every 2 years, others every year' [S6], revealing that there is no uniformity in the assessment process. The employee appraisal cycle is 'closed' because it is not accompanied by an employee improvement system. In relation to teaching and organisational activities, apart from very poorly developed practices of annual awards, even good practices are lacking.

A major setback in the implementation of an effective PA is the lack of consequences that emerge if performance is weak. In cases when scientific activity was poor or not present, there were no consequences. One example was given by our key informant:

'The scientific assessment system is not effective, because the consequences of low scientific activity are poor or none. In the previous parameterisation, we had several examples of N0 [authors: no publication within 4 years] at the faculty and there were no consequences' [U1].

Universities experienced unsuccessful attempts to dismiss employees after repeated negative assessments and awards at a faculty level which are given to everyone who published a book, so far without any gradation as to its scope and value. According to one respondent:

'I have experience in unsuccessful attempts to dismiss employees after repeated negative assessments of supervisors and students, it failed. Awards at the Faculty are given to everyone who published a book, so far without any gradation as to its scope and value' [U3].

Ad. RQ 2. Who is appraised-individual vs. collective performance?

2.1. What kind of PA initiatives were introduced and implemented in universities?

The main PA activities relate to the scientific activities of research and teaching staff. The following statements made by respondents highlight these views:

'A certain novelty in our faculty is to be awarded only to high-ranking publications of international employees' [U3].

'There is also an evaluation of someone's publication when s/he applies for a promotion (especially from Senior Lecturer grade to Associate Professor). Also, there is a system where funds (up to 50,000 euro) are given to academics for projects, after an evaluation of proposals is made' [C2].

The only incentives which are used are predominantly financial, as noted by respondents: 
'Financial motivators are used such as one-off scholarships which are a specific injection of cash and scholarship for high-score publications' [S1].

'There are mostly financial motivators: Rector's award, scholarship for publications, but also non-financial-reduction of teaching hours for participation in the project' [S2].

These incentives are the same for everyone, they do not differentiate the researchers' input, effort and discipline he/she represents, which gives the impression of social injustice and having reached the certain level of promotion, they do not work anymore, as respondents mentioned:

'There are very few incentives beyond promotion. Of course, once an academic reaches the top of the ladder, that incentive disappears. There used to be a bonus structure based on performance in three key areas including research that was abolished some 10 years ago' [U5].

The measurement of scientific achievements is carried out in accordance with the principles contained in legal regulations imposed by the Ministry of Science and Higher Education (laws, regulations). The measurement based on scientometrics and the point system for publications is used for research exercise, which evaluates scientific disciplines at universities:

'I think that the most widely used performance systems are metric-based, pertaining to the quantity of peer-reviewed publications. Apart from this type of performance system, the quantification of lecturing hours and supervision is also used to gauge how much an academic 'should be' working. Moreover, consideration is taken of research projects/funding applications an academic is involved in; and any official position an academic holds and how the research output of academics helps universities go further up in rankings' [U2].

Respondents had a feeling of system dissonance which might be described by their experiences:

'Times are such that non-financial motivators do not work, people want money for everything even for what they have inscribed in their duties. I see a problem here because I think that people who know the university ethos should work at the university' [S4].

'I would see a researcher being stimulated and supported all the time and not only after financial award' [S1].

Ad. 2.2. Is the PA individual or collective?

In relation to RQ 2.2, it could be said that scientific assessments are primarily individual. The evaluation of a scientific discipline at a university is an aggregated assessment of individual scientific achievements and, to a lesser extent, implementation. That can be exemplified by key informants: 'Mainly publications of individual scholars are awarded, customary monographs at our Faculty' [U2]. 'In social sciences, especially the humanities, the output, publications and grants are rather individual' [U1].

'On the other hand, however, scientific categories will be awarded to universities solely for scientific disciplines consisting of teams of scientists (the so-called Number $\mathrm{N}$ in the discipline), what was remarked upon by one respondent: 'We lack an individual approach to everyone, for now, we measure in groups, disciplines, faculties' [S6].

The university's problem will be translating the discipline's assessments into a system that motivates researchers. Approximately 20 percent in the assessment of the collective scientific discipline at the university in Poland is an impact on the socioeconomic environment, which is used for expert assessment of collective scientific, implementation or popularising achievements. The evaluation of teaching work is carried out through the evaluation of students, superiors, deans and external evaluators.

Ad. RQ 3. Why is performance management used-administrative vs. developmental purposes?

Ad. 3.1 Is there a tension between universities' and governmental agencies' views on performance appraisal?

Answering the RQ 3.1, it can be stated that reporting at the employee level mainly relates to scientific activities (publications, grants), and to a lesser extent, to teaching activities (syllabuses, study documentation). Managers at the central level see the need to increase scientific reporting and implement an integrated system of scientific activities, but there are some historical obstacles which delay the new approach: 
'Limiting myself to only two KPIs (publications and participation in grants), which I have indicated, is insufficient for assessing the effectiveness of this system and we need more parameters to evaluate scientific progress, but our problem is that we are at an early stage of development of this approach because several decades before we operated differently' [S5].

At the level of faculties, institutes and departments, management are overloaded with reporting that is stated by one of the respondents:

'I believe that a managerial level should be introduced to manage teams or departments to relieve department managers from administrative and bureaucratic work. It should, therefore, be a Product manager-scientist responsible for a substantive input, idea, research and project manager supervising tenders, procedures, signatures, etc.' [S3].

Ad. 3.2 Is there an internal need for rational management by performance indicators or external pressure (e.g., government) forcing universities to carry out PA?

In relation to RQ 3.2, performance indicators do not yet work in scientific or teaching activities, and they are mostly focused on financial incentives, while according to our respondent: 'New tools can be effective but it takes time to evaluate them. The proposals that are in various projects are focused on financial motivation, but this motivator does not work logically-it is good for a short time' [S2]. Moreover, new government regulations create the conditions for scientific competition between different universities in scientific disciplines according to one template. This mechanism should translate into the creation of performance indicators at universities. The following remark help explain the respondents' feeling of system:

'The big problem in assessing scientific achievements is the differences between different sciences, humanists write books, artists create works, technical sciences implementations, and scientists create papers in journals. The Ministry is trying to impose one framework, but this does not work out... hence the humanities protest committees and there is general frustration' [U2].

Ad. RQ 4. How is PA perceived by the academic community-a tool for performance improvement vs. bureaucratic machine?

The fourth research question put forward in this study addresses the view of academic community on PA. Answering this question might allow us to gain new insights into how PA influences the motivation of the public universities employee, and, in particular, if it enhances PSM or diminishes it and turns it into an instrumental motivation. The bureaucratic role of PA might be summarised in two main points. First, it seems that PA is not fully accepted by the public universities community, as the following quotations shows: 'All employee appraisal at the bill level is a bureaucratic obligation' [U14]. 'Practically the employee evaluation system was forced upon us by a ministerial act' [U12].

Ad. 4.1 Which factors inhibit universities in the PA process? Are these internal or external factors?

The view of PA as something externally imposed on the academic community was mentioned by our key informant: 'The authorities are forcing more and more scientific bureaucracy, it was supposed to be de-bureaucratic, or rather the opposite, more and more scientific reporting' [U3], which leads to resistance among the university community and might undermine the accuracy of the whole PA process. If researchers do not accept the idea of PA and do not see the goals behind it as reasonable, they might try to develop different research and publications strategies in order to 'play the system' and by, doing so, gain high PA scores but not to improve their performance. Inhibitors in PA process are also noted on internal and external levels.

Ad. 4.2 Is PA focused on accountability and assessment only or on development of employee performance?

PA is seen as too heavily focused on assessment, control and research accountability but leaving alone issues related to researchers' professional development. This view was supported by a respondent:

'Researchers would be motivated if all their activities were taken into account in performance systems, i.e., not just their teaching hours and publications, but also their work in organising/attending conferences; doing review or editorial work for journals; drafting funding proposals; contributions to industry; social engagement and public appearances; committee memberships; student satisfaction with their work' [U2]. 
It was also confirmed in other studies [42]. Although there are different attempts and means to appraise public universities researchers' performance, there are few or no guidelines and little assistance from the appraisal system itself of how, based on those appraisal results, researchers may develop their abilities or motivation to perform better science, which was mentioned by another respondent: 'Employee appraisals do not have special developmental aspects because of a dominant friendly and collegial approach that does not encourage developmental talks based on documentation and evidence' [U15].

\section{Discussion}

In this study, we aimed to analyse the possible role of the PA system introduced by NPM on public universities on academics' PSM. We based our analysis on interviews with key informants with university organisational structures and drew our conclusions from their personal perception of PA and motivation systems implemented in their universities. The result derived from our research was that the performance appraisal seems to be mainly symbolic, which means that PA practices were actually reinforced by external pressures for legitimacy and accountability, as also argued by Decramer et al. [25]. PA is seen rather as externally forced: 'another' invention of government and funding agencies rather than the tool that is wanted by the research community and might really help HEIs boost their performance, as was claimed by Decramer et al. [25]. Thus, it might be stated that PAs are perceived by the public universities' key informant rather as a tool that increases bureaucracy rather than a method to improve performance.

It might be also observed that PA is usually not a part of the whole performance management system along with feedback, training, mentoring and goal setting, but a PA is the end in itself as it was noticed by Murphy [28]. PA is usually used to get research ranked and assessed, not to diagnose their problems or work difficulties and help them to overcome it. Therefore, although PAs are often described as having been designed mainly to improve researchers' motivation and performance level, in reality they are often concentrated on accountability and assessment for administrative purposes, e.g., calculating pay raises, promotion in university's structures, research funding accounting, etc.

Taking into account the perspectives on PA that arise among key informants on public university, it might be suggested that PA might undermine the public service motivation (PSM) that initially drove researchers working for public HEIs. There is a tension visible between the eagerness to measure the scientific achievements of academic managers and accountability of individual performance in academia and PSM scholarship. It can be described as 'system dissonance,' where one who was primarily motivated by the university ethos to serve the interests of an academic community [52] has been pushed to 'produce' scientific works which are visible and accountable (in points, indexes, etc.). However, these 'hard data' and evaluation results rarely have any impact on employee career development [53].

According to Gellaty [23], the current challenges faced by universities (fashion for metrics and analytics, accountability) and the effects of these on their staff may well reduce both the belief in the mission and the confidence of the future of the organization. That is not to say that PSM does not matter; for some academic disciplines, notably social sciences, it is a significant predictor of performance.

\section{Conclusions}

There are at least five important conclusions stemming from our analysis. First, it can be said that all three examined universities are in phase 2 (Figure 1) of the development of incentive systems. PA techniques have been introduced on an ad hoc basis, and a PA system is perceived to be just a facade, as symbolic.

Secondly, incomplete and loosely coupled practices of motivating researchers are based mainly on short-term financial incentives, annual awards, funds for research grants. There is no bonus system or employee development system. Motivational and developmental practices are individual, based on senior and scientific authority. The existing forms of PA are usually introduced in universities for 
administrative purposes, forced by internal or external regulations (external authorities-government, agencies) which expect statistics, numbers, rankings. This practice may lead to what Bögner et al. [54] termed as the growing obsession of higher education institutions with rankings, and what Van der Zwaan [55] noticed: that universities have become the prisoners of the league tables.

Thirdly, PA that is intended to provide researchers with job resources to improve their engagement and motivation has instead resulted in creating a bureaucratic burden, confirmed also by Angiola et al. [56]. The emphasis is mainly on accountability and assessment, and not for development. Universities are placing increasing emphasis on research performance indicators, rather than valuing and appreciating engagement, the individual dedication and commitment of their employees who will be able to build trustworthy relationships in international teams of researchers (see [57]).

Fourthly, PA, instead of providing job resources to deal with job difficulties and helping to attain work goals, seems to cause hindrances to work and yet more demands that consume researchers' energy, generate stress and might result in undermining motivation. For example, researchers initially driven by PSM as a need for contributing to the development of society might realise that government and funding agencies do not want a contribution to society, but they do want a high final score in a PA. In this situation, PSM-driven activities are pushed into the background, and the pursuit of evaluation points (top publications, prestigious grants) comes to the foreground. Therefore, due to a PA, the PSM of public universities, researchers might be substituted by instrumental motivation just to attain a high enough PA score.

The fifth conclusion that stems from analysis of our questions for PSM scholarship is that the perception of PA among key informants seems to be at odds with the perception of PA among government agencies and funding bodies forced to use it. Key informants on public universities seem to see PA rather as a bureaucratic burden, but the government, in line with the NPM movement, seems to see PA as a vital part of public HEI research accountability and an important factor in human resource management leading to employee motivation and performance improvement (see $[24,25,41]$ ).

The challenge for policymakers and public managers in HEIs is to rethink traditional assumptions about employee motivation and adopt strategies that complement rather than undercut PSM [39]. Our recommendation for university managers and policymakers to make better connection between PA and PSM would be also to form/build a supportive professional and administrative community for these academics who seek the public good in their daily work.

It could be also an appeal to create such an organisational culture that promotes clear university mission and incentivise engagement in building trustful relationships in research teams so that many individuals with PSM were encouraged to enter public universities.

Our results might be an opportunity for public managers to harness the concept of PSM, especially with regards to young academic talents who experience organizational obstacles to developing PSM, as pointed out by Leisink et al. [58], Houston [59] and Ingrams [53]. This would be an important issue to be considered by public managers as there is also evidence found by Breitsohl et al. [60] that PSM is much higher with millennial workers, explaining their attraction to seek employment in the not-for-profit sector.

\section{Limitations and Further Research}

The major limitation of this study is the use of a relatively small sample of universities and convenience sampling. However, this small sample was homogenous; all these universities are middle-class public universities aiming for performance improvements. Thus, although our findings might not be generalisable to all universities, they might yield interesting insights into the functioning of middle-class public universities. The convenient sample was dictated by the fact that the three authors of this paper were long-term employees of those mentioned universities, which gives them the unique insider perspectives on the issue at hand. The authors' long-term experience as employees at the investigated universities was an important factor in gathering valid information and asking insightful questions from a key informant of the universities. The readers should also bear in mind 
that the study is based on subjective self-reported opinions of university employees on positions of key informants and, as based on this, we might analyse how informants personally perceive the PA role for performance improvements, but further data collection from researchers on an individual level is required to determine how perceptions of the PA system among the academic community affect individual academic performance. In this study, we were not analysing opinions of individual researchers, but we have analysed perception on PM by key informants, as we believed that the specific position of key informants in the organisational structure allows for drawing valuable insights on organisational and individual levels.

We believe that, despite its limitations, this paper might be seen as putting forward important research questions about the role of PA in universities and sparking further debate on the possible unintended consequences of performance improvements practices. We would like to invite future studies to replicate and extend our findings by unravelling the complex mechanisms through which PA might influence PSM. This might be valuable to confront our findings with further studies on the level of individual researchers conducted in the quantitative approach and based on more universities. Although our study is not free from limitations, we hope that it might provide educational sciences scholars with some valuable insights, highlight import research questions and inspire debate on the dark side of PA in public universities.

Author Contributions: Investigation of background knowledge, Ł.S., S.P.; investigation of online discussions, C.B., K.K.; writing—original draft preparation, Ł.S., S.P.; writing-review and editing, C.B. and K.K.; interviews and participant observations, C.B., Ł.S., S.P. All authors have read and agreed to the published version of the manuscript.

Funding: This research received no external funding.

Conflicts of Interest: The authors declare no conflict of interest

\title{
Appendix A
}

Table A1. Description of the three universities.

\begin{abstract}
Jagiellonian University (JU) is the oldest Polish university, founded in $\mathbf{1 3 6 4}$ and perceived as a national heritage. It is a comprehensive University educating and conducting research in over 30 scientific disciplines in 16 faculties. It is listed second in Poland in terms of scientific achievements and has ambitions of global development. JU has more than 41,000 students, and 3800 academic staff in 28 scientific disciplines. The JU cooperates with $\mathbf{2 4 0}$ partner universities in $\mathbf{5 2}$ countries. The JU is the member of following international associations: EUA, Unaeuropa, Coimbra Group, Aucso, Baltic University Programme, Eunis, The Guild, Europaeum, Sar.
\end{abstract}

\footnotetext{
Wrocław University of Economics (WUE) was founded in 1947 in Wroclaw as a one-faculty school. Presently, WUE is one of the top public economic schools of higher education in Poland and has 4 faculties. It has more than 17,000 students and 550 academic staff.

WUE is the member of international institutions (European University Association, Global Division Santander Universidades, CFA Institute, European Institute for Advanced Studies in Management) and cooperates with 204 universities based in 27 European countries and in the USA and China.
}

The University of Malta (UM) lies at the middle of the Mediterranean and it was established in 1769. At UM, academic research is carried out that provides a vibrant higher education setting in the arts, sciences and the humanities. Courses are designed to produce highly qualified professionals in more than 120 academic disciplines. The total student population of the University is $\mathbf{1 2 , 0 0 0}$ and it employs around $\mathbf{3 0 0 0}$ academic staff. Today, UM is composed of $\mathbf{1 4}$ faculties, 18 institutes, 13 centres and 3 schools. Besides the main campus, situated at Msida, there are three other campuses: Valletta, Marsaxlokk, Gozo.

The University of Malta is a member of the European University Association, the European Access Network, Association of Commonwealth Universities, the Utrecht Network, the Santander Network, the Compostela Group, the European Association for University Lifelong Learning (EUCEN) and the International Student Exchange Programme (ISEP). The University of Malta has over 1500 bilateral agreements with universities across the world, from which 1100 are Erasmus agreements. 


\section{Appendix B}

Table A2. Extraction of quotations related to each research questions.

\section{How is performance appraisal used-symbolic vs rational performance appraisal}

1.1 Is the performance appraisal system seen as a symbolic or rational. i.e., is performance appraisal used only to "symbolize" to external sites (e.g., government, funding agencies, etc.) that HEI act in rational, progressive, accountable manner but with any rational use for internal HR development purpose?

\begin{tabular}{|c|c|}
\hline Citation & Respondent \\
\hline $\begin{array}{l}\text { "You can't talk about the system-what we do results from the parameterization and } \\
\text { indicators that were shown there. There was also no comprehensive assessment attempt at } \\
\text { a university other than parameterization." }\end{array}$ & [S1] \\
\hline $\begin{array}{l}\text { "We are still in our infancy but all the tools created are moving towards the evaluation of } \\
\text { scientific performance." }\end{array}$ & [S3] \\
\hline $\begin{array}{l}\text { "We cannot say that we have a system-there are only elements on which this system can be } \\
\text { built." }\end{array}$ & [S4] \\
\hline $\begin{array}{c}\text { "We can't talk about a systemic approach, we only have tools (...). Some scholars are } \\
\text { evaluated every } 2 \text { years, others every year." }\end{array}$ & [S6] \\
\hline $\begin{array}{l}\text { "The scientific assessment system is not effective, because the consequences of low scientific } \\
\text { activity are poor or none. In the previous parameterization, we had several examples of N0 } \\
\text { [authors: no publication during } 4 \text { years] at the faculty and there were no consequences." }\end{array}$ & [U1] \\
\hline $\begin{array}{l}\text { "Universities are faced with a situation where the dismissal of an employee at a public } \\
\text { university is a nightmare especially when trade unions are involved and appeals are } \\
\text { lodged in court cases." }\end{array}$ & [U2] \\
\hline $\begin{array}{l}\text { "I have experience in unsuccessful attempts to dismiss employees after repeated negative } \\
\text { assessments of supervisors and students, it failed. Awards at the Faculty are given to } \\
\text { everyone who published the book, so far without any gradation as to its scope and value." }\end{array}$ & [U3] \\
\hline $\begin{array}{l}\text { "With such direct methods of employee appreciation, I don't actually have it, there is no } \\
\text { bonus, although partial compensation may be money intended for trips." }\end{array}$ & [U4] \\
\hline $\begin{array}{l}\text { "The only evidence-based performance system is that of the promotions exercise for } \\
\text { academic members of staff. Research output is one of the main three criteria for promotion } \\
\text { from one grade to another." }\end{array}$ & [C4] \\
\hline $\begin{array}{l}\text { "I am not aware that my university has other measures than those used for the promotion } \\
\text { system of a resident academic." }\end{array}$ & [C1] \\
\hline
\end{tabular}

\section{Who is appraised-individual vs collective performance}

How possible it is to synchronise individual with collective performance? Is it a case of a silo mentality?

\subsection{What kind of performance appraisal initiatives were introduced and implemented in HEI}

\footnotetext{
"The only motivation system is the promotion system. In the current collective agreement regulating employment by the university, academics need to publish a minimum number of research papers in order to be promoted to associate professor. This system has the advantage of encouraging academics to engage in research, however, it can be very disheartening for academics in high cost research areas to need the same number of publications to progress when there is no funding for consumables, equipment and research staff to enable them to generate sufficient, good quality data to publish. The lack of funding to pay publication charges (including open access) is also a serious limiting factor." 
Table A2. Cont.

"I think that the most widely used performance systems are metric-based, pertaining to the quantity of peer-reviewed publications. Apart from this type of performance system, the quantification of lecturing hours and supervision is also used to gauge how much an academic 'should be' working. Moreover, consideration is taken of research

projects/funding applications an academic is involved in; and any official position an

academic holds and how the research output of academics helps universities go further up in rankings."

"Department is obliged to periodically (every year or two) to submit a self-assessment on the work it is doing, its publications, and initiatives in which it participates.

There is also an evaluation of someone's publication when s/he applies for a promotion

(especially from Senior Lecturer grade to Associate Professor). Also, there is a system

where funds (up to 50,000 euro) are given to academics for projects, after an evaluation of proposals is made."

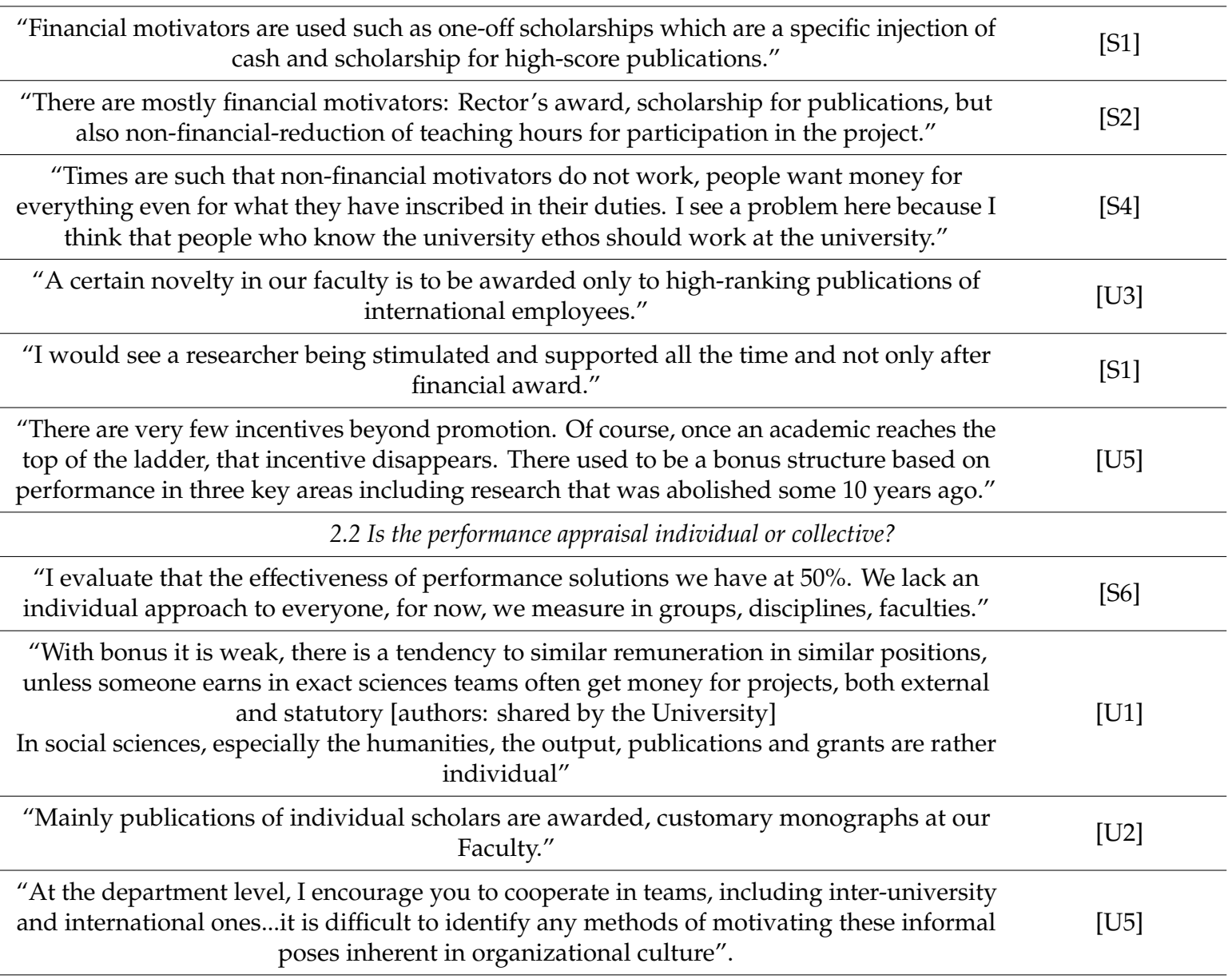

3. Why is performance management used-administrative vs developmental purposes?

3.1 Is there a tension between HEI and governmental agencies view on performance appraisal?

"These best practices need to be used in order to stimulate a healthy academic culture where the university showcases its work and expertise. Such systems should not create the feeling among academics that they are in place in order to police their work; because such an approach will lead to the privileging of quantity over quality, where academics over time begin 'playing the game' to ensure they score highly on these performance systems, especially when these systems play an important role in being granted promotions".

"Limiting myself to only two KPIs (publications and participation in grants), which I have indicated, is insufficient for assessing the effectiveness of this system and we need more parameters to evaluate scientific progress, but our problem is that we are at an early stage 
Table A2. Cont.

"I believe that a managerial level should be introduced to manage teams or departments to
relieve department managers from administrative and bureaucratic work. It should,
therefore, be a Product manager-scientist responsible for a substantive input, idea, research
and project manager supervising tenders, procedures, signatures, etc."
[S3]
"At the management level, it would be good to have more knowledge about the academic
achievements of the university...we need a good scientific reporting system".
[U1] forcing HEI to do performance appraisal?
3.2 Is there an internal need for rational management by performance indicators or external pressure (e.g., government)
"New tools can be effective but it takes time to evaluate them. The proposals that are in
various projects are focused on financial motivation but this motivator does not work
logically-it is good for a short time."

"In addition to financial motivators, I think that the very motivator is the very nature of work (task time, quiet and stable work), and the desire to teach others that results from a sense of agency. Also, the ethos of the researcher and positioning himself in society in this category is an ennoblement and an opportunity for continuous development."

"The big problem in assessing scientific achievements is the differences between different sciences, humanists write books, artists create works, technical sciences implementations, and science creates papers in journals. The Ministry is trying to impose one frame, but this does not work out...hence the humanities protest committees and there is general frustration."

\begin{tabular}{|c|c|}
\hline \multicolumn{2}{|c|}{$\begin{array}{l}\text { 4. How is performance appraisal perceiver by academic community-tool for performance improvement } \\
\text { vs bureaucratic machine? } \\
4.1 \text { Which factors inhibit HEI in performance appraisal process? Are those internal or external factors? }\end{array}$} \\
\hline $\begin{array}{l}\text { "The authorities are forcing more and more scientific bureaucracy, it was supposed to be } \\
\text { de-bureaucratic, or rather the opposite, more and more scientific reporting." }\end{array}$ & [U3] \\
\hline "Practically the employee evaluation system was forced upon us by a ministerial act". & [U12] \\
\hline "All employee appraisal at the bill level is a bureaucratic obligation." & [U14] \\
\hline \multicolumn{2}{|c|}{4.2 Is performance appraisal focus on accountability and assessment only or on development of employee performance? } \\
\hline $\begin{array}{l}\text { "Employee appraisals do not have special developmental aspects because of a dominant } \\
\text { friendly and collegial approach that does not encourage developmental talks based on } \\
\text { documentation and evidence." }\end{array}$ & [U15] \\
\hline $\begin{array}{l}\text { "There is also an evaluation of someone's publication when s/he applies for a promotion } \\
\text { (especially from Senior Lecturer grade to Associate Professor)." }\end{array}$ & $\mathrm{U} 2$ \\
\hline
\end{tabular}

"Researchers would be motivated if all their activities were taken into account in performance systems, i.e., not just their teaching hours and publications, but also their work in organizing/attending conferences; doing review or editorial work for journals; drafting funding proposals; contributions to industry; social engagement and public appearances; committee memberships; student satisfaction with their work."

\section{References}

1. Aguinis, H. Performance Management; Pearson Prentice Hall: Upper Saddle River, NJ, USA, 2009.

2. Ramírez, Y.; Manzaneque, M.; Priego, A.M. Formulating and elaborating a model for the measurement of intellectual capital in Spanish public universities. Int. Rev. Adm. Sci. 2017, 83, 149-176. [CrossRef]

3. Sułkowski, Ł. The culture of control in the contemporary university. In The Future of University Education; Izak, M., Kostera, M.Z., Eds.; Palgrave Macmillan: London, UK, 2017; pp. 85-108.

4. Secundo, G.; Dumay, J.; Schiuma, G.; Passiante, G. Managing intellectual capital through a collective intelligence approach: An integrated framework for universities. J. Intellect. Cap. 2016, 17, 298-319. [CrossRef]

5. Alach, Z. The use of performance measurement in universities. Int. J. Public Sect. Manag. 2016, 30, $102-117$. [CrossRef] 
6. Birdsall, C. Performance management in public higher education: Unintended consequences and the implications of organizational diversity. Public Perform. Manag. Rev. 2018, 41, 669-695. [CrossRef]

7. Herdlein, R.; Kukemelkb, H.; Turk, K. A survey of academic officers regarding performance appraisal in Estonian and American universities. J. High. Educ. Policy Manag. 2008, 30, 387-399. [CrossRef]

8. Kallio, K.; Kallio, T.; Grossi, G. Performance measurement in universities: Ambiguities in the use of quality versus quantity in performance indicators. Public Money Manag. 2017, 37, 293-300. [CrossRef]

9. Field, L. Appraising academic appraisal in the new public management university. J. High. Educ. Policy Manag. 2015, 37, 172-189. [CrossRef]

10. Sułkowski, Ł. Accountability of university: Transition of public higher education. Entrep. Bus. Econ. Rev. 2016, 4, 9-21. [CrossRef]

11. Haughney, K.; Wakeman, S.; Hart, L. Quality of feedback in higher education: A review of literature. Educ. Sci. 2020, 10, 60. [CrossRef]

12. Andersen, L.; Heinesen, E.; Pedersen, L. How Does Public Service Motivation Among Teachers Affect Student Performance in Schools? J. Public Adm. Res. Theory 2014, 24, 651-671. [CrossRef]

13. Jin, M.; McDonald, B.; Park, J. Does Public Service Motivation Matter in Public Higher Education? Testing the Theories of Person-Organization Fit and Organizational Commitment Through a Serial Multiple Mediation Model. Am. Rev. Public Adm. 2018, 48, 82-97. [CrossRef]

14. Perry, J.; Brudney, J.; Coursey, D.; Littlepage, L. What Drives Morally Committed Citizens? A Study of the Antecedents of Public Service Motivation. Public Adm. Rev. 2008, 68, 445-458. [CrossRef]

15. Stefurak, T.; Morgan, R.; Johnson, R.B. The Relationship of Public Service Motivation to Job Satisfaction and Job Performance of Emergency Medical Services Professionals. Public Pers. Manag. 2020, 2020, 009102602091769. [CrossRef]

16. Breaugh, J.; Ritz, A.; Alfes, K. Work motivation and public service motivation: Disentangling varieties of motivation and job satisfaction. Public Manag. Rev. 2018, 20, 1423-1443. [CrossRef]

17. Vandenabeele, $W$. The mediating effect of job satisfaction and organizational com-mitment on self-reported performance: More robust evidence of the PSM-Performance relationship. Int. Rev. Adm. Sci. 2009, 75, 11-34. [CrossRef]

18. Naff, K.C.; Crum, J. Working for America: Does public service motivation make a difference? Rev. Public Pers. Adm. 1999, 19, 5-16. [CrossRef]

19. Perry, J.; Wise, L. The Motivational Bases of Public Service. Public Adm. Rev. 1990, 50, 367-373. [CrossRef]

20. Bright, L. Public service motivation and socialization in graduate education. Teach. Public Adm. 2016, 34, 284-306. [CrossRef]

21. Prysmakova, P.; Vandenabeele, W. Enjoying police duties: Public service motivation and job satisfaction. J. Police Crim. Psychol. 2019, 2019, 1-14. [CrossRef]

22. Sutton, N.C.; Brown, D.A. The illusion of no control: Management control systems facilitating autonomous motivation in university research. Acc. Financ. 2016, 56, 577-604. [CrossRef]

23. Gellatly, L.; D'Alessandro, S.; Carter, L. What can the university sector teach us about strategy? Support for strategyversus individual motivations to perform. J. Bus. Res. 2020, 112, 320-330. [CrossRef]

24. Ter Bogt, H.J.; Scapens, R.W. Performance Management in Universities: Effects of the Transition to More Quantitative Measurement Systems. Eur. Acc. Rev. 2012, 21, 451-497. [CrossRef]

25. Decramer, A.; Smolders, C.; Vanderstraeten, A.; Christiaens, J. The Impact of Institutional Pressures on Employee Performance Management Systems in Higher Education in the Low Countries. Br. J. Manag. 2012, 23, S88-S103. [CrossRef]

26. Denisi, A.S.; Murphy, K.R. Performance appraisal and performance management: 100 years of progress? J. Appl. Psychol. 2017, 102, 421-433. [CrossRef]

27. Gerrish, E. The Impact of Performance Management on Performance in Public Organizations: A MetaAnalysis. Public Adm. Rev. 2016, 76, 48-66. [CrossRef]

28. Murphy, K.R. Performance evaluation will not die, but it should. Hum. Resour. Manag. J. 2020, 30, 13-31. [CrossRef]

29. Pulakos, E.D.; Hanson, R.M.; Arad, S.; Moye, N. Performance management can be fixed: An on-the-job experiential learning approach for complex behavior change. Ind. Organ. Psychol. 2015, 8, 51-76. [CrossRef]

30. Schleicher, D.J.; Baumann, H.M.; Sullivan, D.W.; Yim, J. Evaluating the Effectiveness of Performance Management: A 30-Year Integrative Conceptual Review. J. Appl. Psychol. 2019, 7, 851. [CrossRef] [PubMed] 
31. Tziner, A.; Rabenu, E. Beyond performance appraisal: To performance management and firm-level performance. Improv. Perform. Apprais. Work 2018, 8, 190-205.

32. O'Boyle Jr., E.; Aguinis, H. The best and the rest: Revisiting the norm of normality of individual performance. Pers. Psychol. 2012, 65, 79-119. [CrossRef]

33. Iqbal, M.Z.; Akbar, S.; Budhwar, P. Effectiveness of performance appraisal: An integrated framework. Int. J. Manag. Rev. 2015, 17, 510-533. [CrossRef]

34. Mayer, R.C.; Davis, J.H. The effect of the performance appraisal system on trust for management: A field quasi-experiment. J. Appl. Psychol. 1999, 84, 123-137. [CrossRef]

35. Dobbins, G.H.; Cardy, R.L.; Facteau, J.D.; Miller, J.S. Implications of situational constraints on performance evaluation and performance management. Hum. Resour. Manag. Rev. 1993, 3, 105-128. [CrossRef]

36. Levy, P.E.; Williams, J.R. The social context of performance appraisal: A review and framework for the future. J. Manag. 2004, 30, 881-905. [CrossRef]

37. Tweedie, D.; Wild, D.; Rhodes, C.; Martinov-Bennie, N. How does performance management affect workers? Beyond human resource management and its critique. Int. J. Manag. Rev. 2019, 21, 76-96. [CrossRef]

38. Sousa, C.A.; de Nijs, W.F.; Hendriks, P.H. Secrets of the beehive: Performance management in university research organizations. Hum. Relat. 2010, 63, 1439-1460. [CrossRef]

39. Ritz, A.; Brewer, G.; Neumann, O. Public Service Motivation: A Systematic Literature Review and Outlook. Public Adm. Rev. 2016, 76, 414-426. [CrossRef]

40. Decramer, A.; Smolders, C.; Vanderstraeten, A.; Christiaens, J.; Desmidt, S. External pressures affecting the adoption of employee performance management in higher education institutions. Pers. Rev. 2012, 41, 686-704. [CrossRef]

41. Cullen, J.; Joyce, J.; Hassall, T.; Broadbent, M. Quality in higher education: From monitoring to management. Qual. Assur. Educ. 2003, 11, 5-14. [CrossRef]

42. Dobija, D.; Górska, A.M.; Grossi, G.; Strzelczyk, W. Rational and symbolic uses of performance measurement: Experiences from Polish universities. Account. Audit. Acc. J. 2019, 32, 750-781. [CrossRef]

43. Baxter, P.; Jack, S. Qualitative case study methodology: Study design and implementation for novice researchers. Qual. Rep. 2008, 13, 544-559.

44. Tran, V.T.; Porcher, R.; Falissard, B.; Ravaud, P. Point of data saturation was assessed using resampling methods in a survey with open-ended questions. J. Clin. Epidemiol. 2016, 80, 88-96. [CrossRef]

45. Francis, J.J.; Johnston, M.; Robertson, C.; Glidewell, L.; Entwistle, V.; Eccles, M.P.; Grimshaw, J.M. What is an adequate sample size? Operationalising data saturation for theory-based interview studies. Psychol. Health 2010, 25, 1229-1245. [CrossRef] [PubMed]

46. Guest, G.; Bunce, A.; Johnson, L. How many interviews are enough? An experiment with data saturation and variability. Field Methods 2006, 18, 59-82. [CrossRef]

47. Aldiabat, K.M.; Le Navenec, C.L. Data saturation: The mysterious step in grounded theory methodology. Qual. Rep. 2018, 23, 245-261.

48. DeWalt, K.M.; DeWalt, B.R. Participant observation. In Handbook of Methods in Cultural Anthropology; Bernard, H.R., Ed.; AltaMira Press: Walnut, Creek, 1998; pp. 259-300.

49. Marshall, M.N. The Key Informant Technique, Family Practice; Oxfor University Press: Oxford, UK, 1996.

50. Kawulich, B. Participant Observation as a Data Collection Method. Forum Qual. Soc. Res. 2005, 6, fqs-6.2.466.

51. Dwyer, S.C.; Buckle, J.L. The space between: On being an insider-outsider in qualitative research. Int. J. Qual. Methods 2009, 8, 54-63. [CrossRef]

52. Rainey, H.G.; Steinbauer, P. Galloping elephants: Developing elements of a theory of effective government organizations. J. Public Adm. Res. Theory Adm. Res. Theory 1999, 9, 1-32. [CrossRef]

53. Ingrams, A. Organizational Citizenship Behavior in the Public and Private Sectors: A Multilevel Test of Public Service Motivation and Traditional Antecedents. Rev. Public Pers. Adm. 2020, 40, 222-244. [CrossRef]

54. Bögner, I.; Petersen, J.; Kieser, A. Is it possible to assess progress in science? In Multi-Level Governance in Universities; Frost, J., Hattke, F., Reihlen, M., Eds.; Springer: Dordrecht, The Netherlands, 2016; pp. 215-231.

55. Van der Zwaan, B. Higher Education in 2040. A Global Approach; Amsterdam University Press: Amsterdam, The Netherlands, 2017.

56. Angiola, N.; Bianchi, P.; Damato, L. Performance management in public universities: Overcoming bureaucracy. Int. J. Prod. Perform. Manag. 2018, 67, 736-753. [CrossRef] 
57. Douglas, A.S. Advice from the Professors in a University Social Sciences Department on the Teaching-Research Nexus. Teach. High. Educ. 2013, 18, 377-388. [CrossRef]

58. Leisink, P.; Steijn, B. Public service motivation and job performance of public sector employees in the Netherlands. Int. Rev. Adm. Sci. 2009, 75, 35-52. [CrossRef]

59. Houston, D.J. Public-service motivation: A multivariate test. J. Public Adm. Res. Theory 2000, 10, 713-728. [CrossRef]

60. Breitsohl, H.; Ruhle, S. Millennials' public service motivation and sector change: A panel study of job entrants in Germany. Public Adm. Q. 2016, 40, 458-489.

(C) 2020 by the authors. Licensee MDPI, Basel, Switzerland. This article is an open access article distributed under the terms and conditions of the Creative Commons Attribution (CC BY) license (http://creativecommons.org/licenses/by/4.0/). 